\title{
VOLATILIDAD DE LOS COMMODITIES MINEROS Y SU INCIDENCIA EN LA ECONOMÍA NACIONAL
}

\section{VOLATILITY OF MINING COMMODITIES AND THEIR INCIDENCE IN THE NATIONAL ECONOMY}

\author{
Nicko Alberto Gomero Gonzales \\ Doctor en Ciencias Económicas - Docente Principal de la Facultad de Ciencias Contables - Universidad Nacional \\ Mayor de San Marcos, Lima, Perú. \\ Email: ngomerog@unmsm.edu.pe (Autor Corresponsal)
}

[Recibido: 25/10/2016 Aceptado: 10/02/2017]

\section{RESUMEN}

El mercado de commodities mineros está anclado al comportamiento de la economía global, especialmente a países como la China y Estados unidos configurados como las primeras potencias económicas en este mundo globalizado. El hecho que la economía peruana en parte muestre alta sensibilidad al precio de los minerales de exportación, abre espacios de vulnerabilidad a las oscilaciones del mercado de este tipo de productos, cuyos efectos se van apreciar en el sector real y financiero de la economía. Por ello a través del método correlacional se llega a determinar y explicar el tipo de relación existente entre el precio de los commodities y las principales cuentas macroeconómicas, resultado que permitirá evidenciar el grado de dependencia de la economía a este tipo de mercado. En el estudio además se evidencia la importancia que tienen los países emergentes, entre ellos la China, como principal demandante y productor de estos tipos de commodities, cuyas fortalezas son factores relevantes en el dinamismo de este mercado.

\section{PALABRAS CLAVE}

Commodities mineros, mercado, precios. Cuentas macroeconómicas, dependencia económica.

\begin{abstract}
The mining commodities market is anchored to the behavior of the global economy, especially to countries like China and the United States configured as the first economic powers in this globalized world. The fact that the Peruvian economy partly shows a high sensitivity to the price of export minerals opens spaces of vulnerability to the market oscillations of this type of products. These effects will be appreciated in the real and financial sector of the economy. Therefore, through the correlation method, we can determine and explain the relationship between the price of commodities and the main macroeconomic accounts, a result that will show the degree of dependence of the economy on this type of market. The study also highlights the importance of emerging countries, including China, as the main demander and producer of these types of commodities, whose strengths are relevant factors in the dynamism of this market.
\end{abstract}

\section{KEYWORDS}

Mining commodities, market, prices, Macroeconomic accounts, economic dependence. 


\section{INTRODUCCION}

Para entender la globalización y la dependencia de los mercados, es necesario recorrer por la teoría de David Ricardo, formulada en el siglo XIX, en donde postulaba la especialización de los países en aquellas actividades en la pudieran tener mayores ventajas comparativas. Este clásico pensador economistas, ya desde esa fecha sentaba las bases para que los países saquen la máxima ventaja del comercio internacional. El contraste se da cuando se observa que las economías llamadas pobres o en vías de desarrollo aun basan su débil crecimiento económico en la exportación de materias primas, especialmente los que proceden de la actividad minera y que no generan mayores posiciones favorables en los mercados globalizados.

Ha quedado evidenciado que todo proceso de desarrollo y el logro de óptimos indicadores macroeconómicos y sociales no pasa por el desarrollo de una industria primaria exportadora, todo lo contrario, existen teorías que sustentan que estos recursos en vez de generar riqueza en las naciones llegan a profundizar desigualdades o asimetrías, tal como sucede en aquellos países con serias deficiencias estructurales, que si bien poseen ventajas comparativas en la explotación y exportación de recursos primarios pero este hecho no se evidencia en el bienestar de sus frente interno.

Ferrufino (2007) señala lo siguiente:

La abundancia de recursos naturales está liderizados por economistas mundialmente reconocidos como Jeffrey Sachs y Andrew Warner. Estos autores demostraron con datos reales relacionados al crecimiento económico de un conjunto importante de países, que existe una relación inversa entre la tasa de crecimiento del Producto Interno Bruto y la dependencia que tiene éste de la producción de recursos naturales. Así, a mayor dependencia del ingreso respecto a los recursos naturales, menor sería, en general, la dinámica del crecimiento económico. A partir de esta evidencia, muchos otros trabajos han revisado esta hipótesis y han determinado matices importantes que cuestionaron los resultados iniciales (p. 6).

Al margen de los hechos sociales y económicos de la explotación de recursos naturales como son los productos mineros, las empresas que exportan estos productos deben estar sujetos a los precios que se formen en los mercados internacionales y por ende su fortaleza económica y financiera va depender de este mercado, cuyas oscilaciones de las dos fuerzas estará mayormente anclada a lo que puedan realizar las principales economías del mundo ya sea como productores o compradores. A fin de cuentas el mercado en este tipo de producto condiciona los efectos hacia las economías con estas ventajas comparativas.

Sobre este último punto es preciso señalar a Nicholson \& Snyder (2015) quien menciona lo siguiente "Alfred Marshall (1842-1924) en (...) sus principios de economía publicado en 1890 demostró que la demanda y la oferta operan simultáneamente para determinar el precio (...), como bien señala el autor, estas dos fuerzas son los que van a marcar tendencias de los precios de cualquier tipo de producto. Como se aprecia, esta ley del mercado guarda aplicabilidad también a los productos que no experimentan pro- cedo de transformación alguna y que son catalogados como tradicionales. Basado en esta teoría del mercado, los países que viven de la explotación de estos recursos tienen que estar condicionado al movimiento de sus dos grandes fuerzas. Perdiendo de esta forma autonomía para sustentar sus acciones de política económica y públicas (p. 11).

Si bien la explotación de minerales ha sido el principal motor de desarrollo de las economías pobres, pero como ya se mencionó, en nada ayudo a resolver los problemas estructurales, pero que si se tradujo en importantes ganancias para las empresas que operan en este rubro, la ruta crítica de crecimiento debe estar por otro lado, tal como se observa en aquellos países que poseen la supremacía económica mundial, como EE.UU, China, Alemania, Japón, entre asiáticos. Sobre este punto cabe mencionar a Dornbush (2015) quien señala: El crecimiento de Hong Kong Singapur Corea del Sur y Taiwán ha sido tan notable que las cuatro naciones se conoce como los tigres asiáticos. Se señala como ejemplo de desarrollo para el resto del mundo. Como se sabe estos países no han crecido por la posesión de recursos naturales sino por la explotación de tecnologías de punta y con ello la creación de industrias con procesos inteligentes (p. 60).

Por ultimo cabe precisar lo que menciona Parkin \& Loria (2010) quienes señalan que: nada es gratis en esta vida (...). El costo de oportunidad es la alternativa de mayor valor a la que renunciamos para hacer algo... todos los intercambios relacionados, con que, como y para quien involucran un costo de oportunidad. Lo señalado por estos autores tratan de explicar que mientras los países pobres sigan 
explotando y exportando recursos naturales, tendrán que asumir ese costo de oportunidad de crecer sostenidamente con mejores alternativas de producción, en donde esté presente el concepto del valor agregado (p. 10).

\section{MATERIALES Y MÉTODOS}

El estudio tiene de tipo causal en ende se correlaciona variables como el PBI de la China con el precio de los minerales, y además con las cuentas fiscales del gobierno. Para analizar el grado y tipo de causalidad se empleó información secundaria lo cual permitió obtener los correspondientes indicadores estadísticos.

\section{RESULTADOS}

Comportamiento de la economía global y las cuentas fiscales

La economía global, liderado por la dos potencias económicas del mundo como son EE.UU y China cuyos PBI son los más importantes del mundo, en los últimos años han presentado movimientos cíclicos, en ciertos periodos con características recesivas que se vieron plasmado en el estancamiento de la economía mundial. El hecho que las principales economías del mundo presenten características contraccionistas en sus indicadores macroeconómicos, por el efecto transmisión, las economías en desarrollo también perciben dichos impactos, generando así un ciclo degenerativo que profundiza la crisis global. Este hecho de dependencia además evidencia cuando las economías que mantienen la supremacía mundial entran al ciclo expansivo de crecimiento que terminan creando escenarios de bienestar en las economías periféricas. Bajo este marco de análisis la interconexión de los mercados con su respectiva correlación se convierte en una amenaza u oportunidad para los países especializados en la explotación y exportación de materias primas.

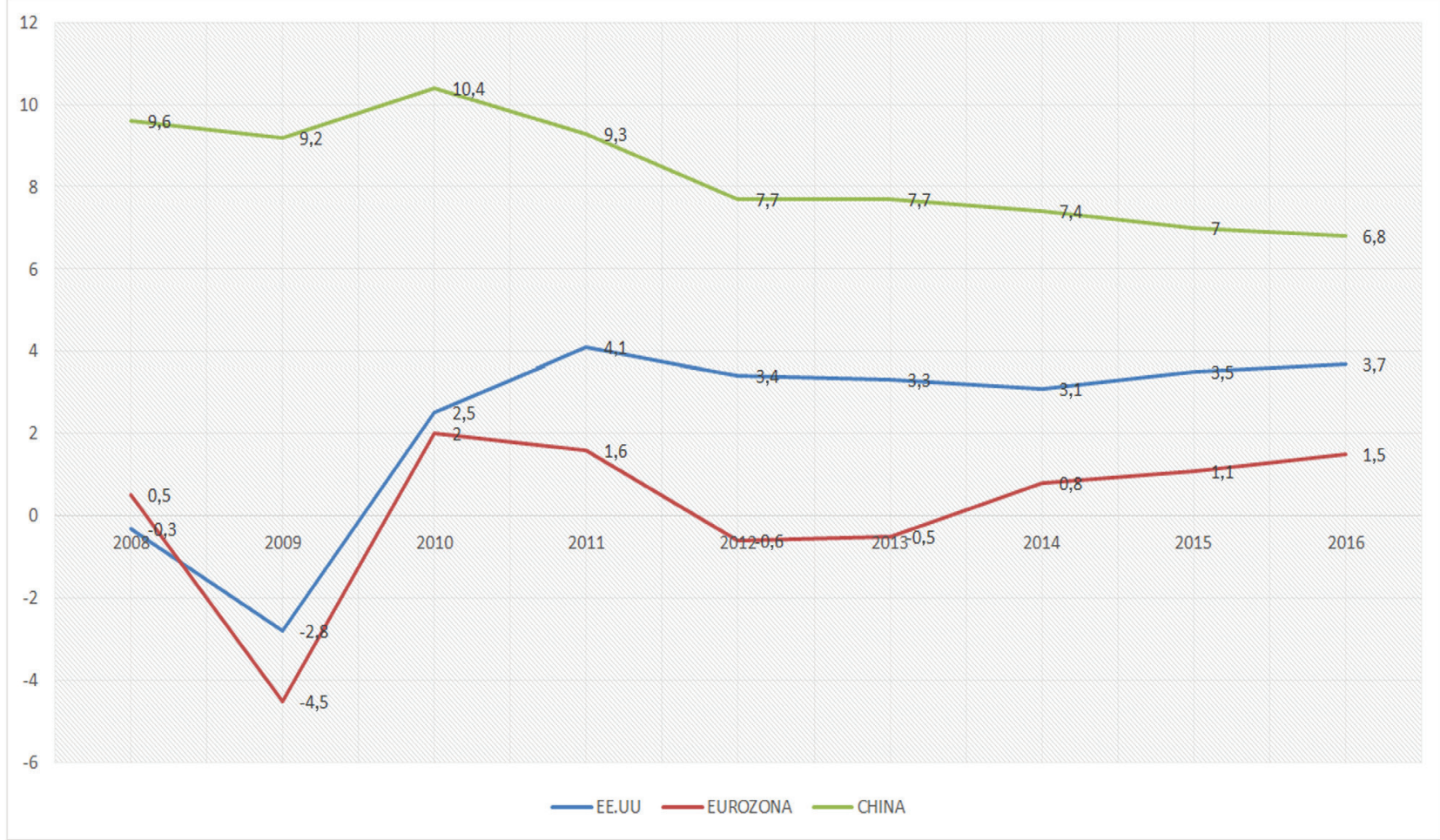

Figura 1. PBI de las principales economías del mundo (\%)

Fuente: FMI 
Tabla 1.

Matriz de correlaciones; PBI de las principales economías del mundo Fuente: FMI / Elaborado por Autor

\begin{tabular}{l|ccc} 
& EE.UU & EUROZONA & CHINA \\
EE.UU & 1 & & \\
EUROZONA & 0,77 & 1 & 1 \\
\cline { 2 - 4 } CHINA & $-0,48$ & $-0,07$ & \\
\hline
\end{tabular}

Tal como se observa en el Tabla 1, el comportamiento de la economía global representada por las economías más importantes del mundo no han sido estable, por un lado se tiene a Estados Unidos, que debido a la crisis financiera del 2009 terminó recesándose y por otro lado se tiene a China que no pudo mantener el ritmo acelerado de sus crecimiento económico, hecho que se evidencia con más cla- ridad en los últimos años, en donde la tasa de crecimiento oscilo entre 7\% y $8 \%$, cifras que representaron cierto quiebre de esta economía emergente.

Peor aún es el caso de Japón cuya plataforma económica está muy lejos de ser calificado como sostenible, las cifras macroeconómicas de este país dan pruebas de la débil eficacia de sus políticas públicas y económicas.
Al estructurar la matriz de correlaciones para el PBI de las principales economías del mundo se puede apreciar que entre la Eurozona, conformada por economías de países como Alemania, Francia, Italia, entre otros y la economía norteamericana existe una alta correlación el cual llega al $\mathrm{R}=0,77 \%$ caso contrario sucede entre la China y Estados Unidos cuyo coeficiente de correlación $\mathrm{R}=-0,48$, cifra que explica que ambas economías no siguen el mismo recorrido en su crecimiento económico, que en cierta forma favorece a las economías con débiles fundamentos económicos como es el Perú, que sustenta su crecimiento en las exportaciones de productos primarios a los mercados asiáticos, como son los minerales.

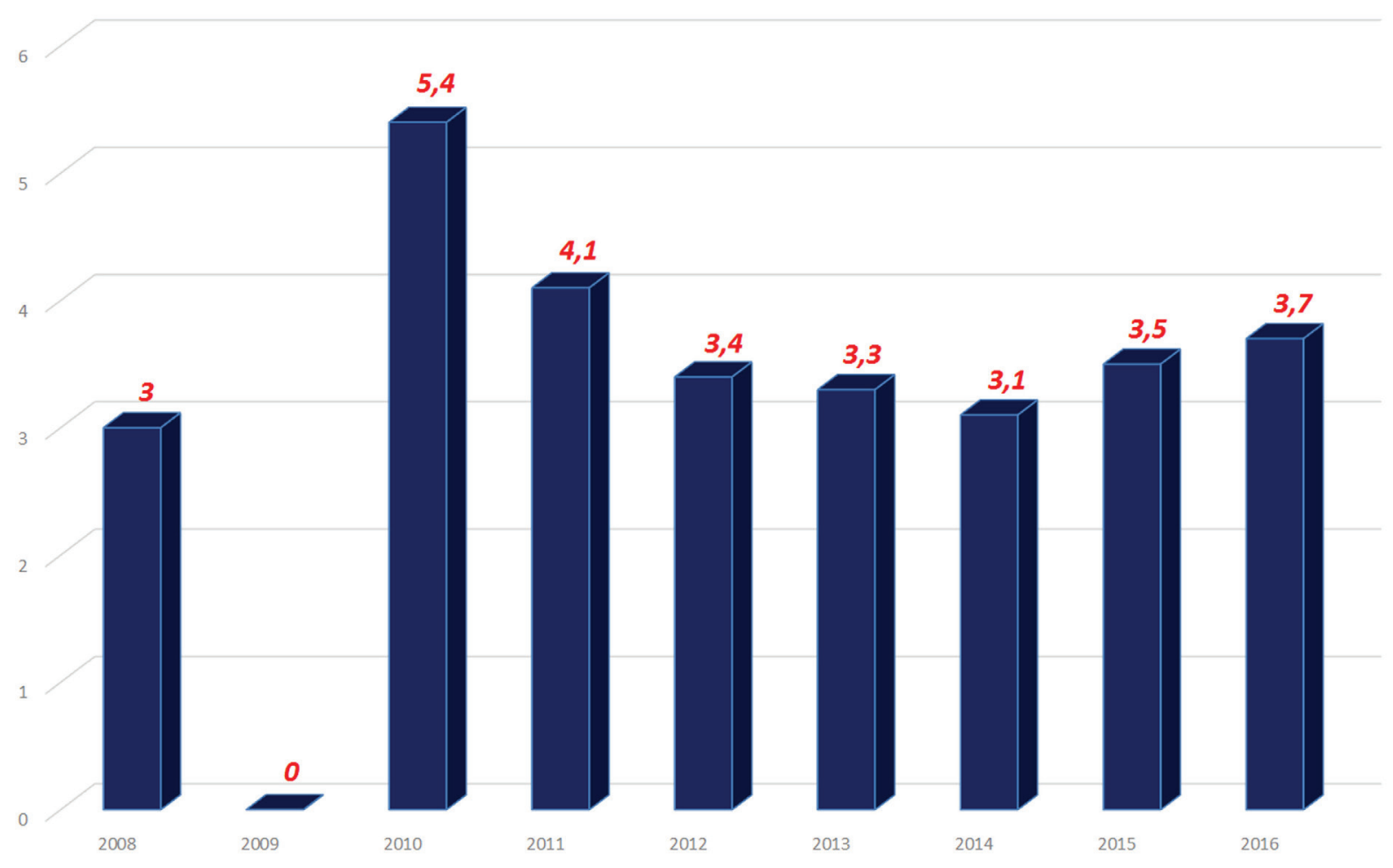

Figura 2. PBI mundial (\%)

Fuente: FMI 
En la Figura 2 se evidencia la debilidad de la economía mundial, lograr una tasa de crecimiento del 3\% como promedio no asegura un despegue de las economías en vías de desarrollos, que como se conoce están ancladas al comportamiento cíclico de las principales economías cuyo comportamiento macroeconómico direcciona la economía del mundo. Estas cifras reflejan el desempeño económico de países como Estados Unidos, China, Alemania, Japón, India, Rusia, que en sí, son las locomotoras del mundo.

No hay que perder de vista que China posee una alta cuota en la exportación de productos terminados y para ello necesita materias primas como son los minerales, por ello tiene que recurrir al mercado de commodities, condicionando de esta forma este tipo de mercado . Por ello se argumenta, que cada posición que tome la China en el mercado de materias primas afectará la tendencia de los precios de estos productos cuyo impacto se reflejará no solo en las cuentas macroeconómicas de los gobiernos, sino también en los indicadores de rentabilidad de las empresas.

Como los mercados no son estables, tampoco las economías, ya que están supeditadas a los ciclos económicos, los precios de los commodities en general tenderán a tener un comportamiento oscilante. La volatilidad de los mismos originará vulnerabilidades en los países exportadores ya que sus cuentas externas y fiscales están ancladas mayormente a la exportación de estos productos.

El comportamiento bajista de las cotizaciones es la que resiente en mayor grado las cuentas macroeconómicas entre ellas las fiscales. Dada la elasti-

cidad de estos productos, conocidos como inelásticos, la baja de los precios se va a transformar en menores ventas

para las empresas exportadoras y con ello pagaran menos impuesto a la renta favor del Fisco.

Tabla 2.

Impuesto a la renta minera y la presión tributaria (2008-2012) Fuente: BCRP / Elaborado por Autor

\begin{tabular}{ccc} 
Años & $\begin{array}{c}\text { Im.Renta minera } \\
(\text { Millones de S/) }\end{array}$ & Presión Tributaria \\
\hline 2008 & 6743 & 16,1 \\
\hline 2009 & 3018 & 14,1 \\
\hline 2010 & 5618 & 15,2 \\
\hline 2011 & 7764 & 15,9 \\
\hline 2012 & 6456 & 16,4 \\
\hline
\end{tabular}

El grado de correlación entre el pago de impuestos por la actividad minera y la presión tributaria, el cual llega al $\mathrm{R}=89 \%$, evidencia la alta dependencia de las cuentas fiscales al comportamiento de los ingresos y beneficios que puedan alcanzar las empresas mineras por sus actividades de exportación, si bien podría representar una vulnerabilidad, pero no deja de representar una importante fuente de recaudación tributaria.

En el Imagen 3 se muestra con claridad en la correlación directa entre estas dos cuentas fiscales, por ejemplo en el 2009, año en que se presentó una importante crisis económica mundial con una fuerte depreciación de los precios de los minerales, la recaudación de impuestos mineros y la presión tributaria siguen el mismo recorrido, que como ya se señaló deterioran las cuentas fiscales o en todo caso generan problemas de caja al gobierno para solventar sus gastos públicos.

El hecho que los precios de los minerales estén ancladas al comporta- miento del mercado internacional, conlleva que una recesión de las principales economías del mundo, o en todo caso la menos demanda de minerales de estos países va a presionar a una caída de los precios de los commodities, fenómeno que se ha de traducir en menores ingresos tributarios de los países que poseen ventajas comparativas en la explotación de estos productos vulnerándose además las cuentas externas como es la balanza comercial

El reacomodo de las cuentas fiscales, materializada por la presión tributaria se hace evidente a partir del 2009 , periodos en la cual, debido a las medidas de ajuste de las economías que habían experimentado impactos negativos de la crisis, el escenario macro económico comienza a presentar algunas señales de crecimiento y con ello también se experimenta una mejora en el precio de los minerales que originara un efecto apalancamiento importante en los ingresos tributarios de gobierno, que contribuyo en cierta forma a cerrar la brecha del déficit fiscal. 


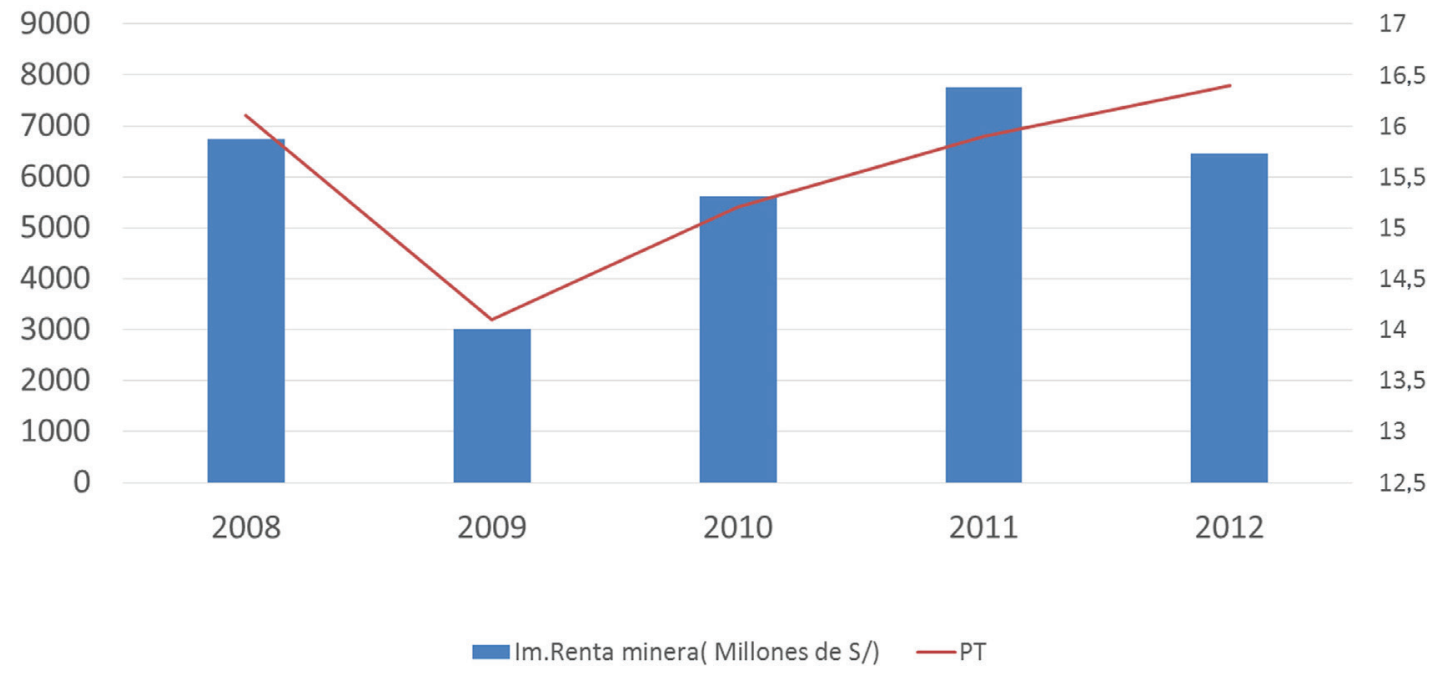

Figura 3. Pago de impuesto a la renta minera y presión tributaria (2008-2012) Fuente: Ministerio de Energía y Minas / Elaboración propia

Esta misma tendencia se observa cuando se analiza la participación de la minería en los tributos internos, en épocas de mejoras de los precios de los commodities la participación de la minería en este tipo de flujos mejora, contribuyendo de esta forma a fortalecer los Ingresos Corrientes del Gobierno Central. Tal como se evidencia en el Imagen 4 los años en la cual se experimenta cambios alcistas en los precios de los minerales, como son el cobre, el zinc, estaño, especial- mente del 2005 al 2008, la recaudación tributaria proveniente por esta actividad es importante alcanzando un pico el 2007, cuya participación de esta actividad en los tributos internos llego al $24,7 \%$, apoyados por la cotización del cobre que alcanzo uno de los precios más altos de los últimos 20 años, el cual fue de $\$ 322,93$ la libra, cifra por cierto que fue menor al 2011, que alcanzo un precio de $\$$ 400,0 . Cabe señalar que este mineral ocupa el primer lugar en el ranking de productos mineros de exportación cuya cuota de aporte a la producción llega al 30,16\%, del zinc 15,39\% y plata $7,34 \%$ respectivamente. Como ya se señaló, el precio de estos productos se mueve por las presiones del mercado, liderado por la China como principal país importador en el mundo, especialmente del cobre, que es utilizado en sus diferentes procesos y sectores productivos.

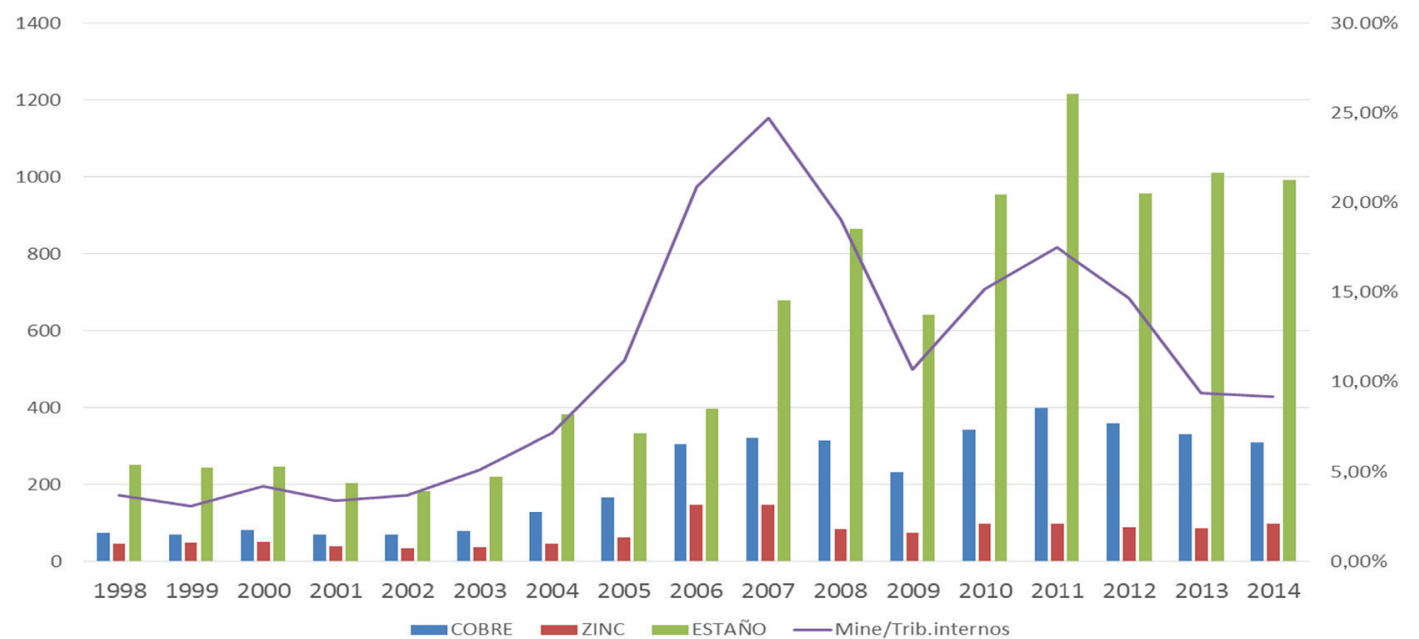

Figura 4. Precio de minerales participación de la minería en tributos internos: 1998-2014 Fuente: Ministerio de Energía y Minas. 
La tendencia de los precios de los minerales y el aporte de la minería en la recaudación tributaria se hace más notoria con el cobre y el Zinc, el cual queda evidenciado con el coeficiente de correlación, llegando para el primer producto el $83 \%$ y el segundo 90,6\% respectivamente, observándose una menor correlación con el estaño el cual llega al 58,5\%. Material que es utilizado desde la industria metálica hasta la de fungicidas y de tintes.

Los coeficientes de correlación señalados, explican o sustentan que los recursos tributarios del Gobierno Central, tan igual como se observa con la presión tributaria, depende de los vaivenes de los precios internacionales de los principales minerales que se exportan. Para este resultado juega un papel importante las elasticidades, siendo caracterizados este tipo de producto como inelásticos, por ello toda caída en las cotizaciones de los minerales se reflejará en menores ingresos para las empresas mineras que se traducirá en menores pagos de impuestos. Cuando el mercado presiona al alza estos precios, los efectos son contrarios, generando mayores ingresos tributarios al gobierno. En la Figura 4, en las tendencias alcistas de los precios, hecho motivado por la creciente demanda internacional de los minerales liderado por las principales economías del mundo, las economías subdesarrolladas o con enclaves importantes de actividad minera fortalecerán sus cuentas fiscales y el PBI.

Como se afirma, la volatilidad de los precios de los commodities está anclada a la demanda del mercado internacional, siendo la china que posee la más alta cuota de participación en el flujo comercial mundial es del $45,48 \%$. Esta fuerza importadora origina que el comportamiento de su actividad económica, medida a través del PBI condicione el comportamiento cíclico del precio de este mineral. Es conocido que este país, después de haber crecido en promedio el $12 \%$, en los últimos años este indicador macroeconómico ha experimentado señales se caídas importantes, hasta llegar a un promedio del 7\%, presionando con ello a la recesión mundial.

Tabla 3.

Matriz de correlación de principales productos mineros y el aporte tributarios de la minería.

Fuente: Elaborado por Autor

\begin{tabular}{lcccc} 
& Cobre & Zinc & Estaño & Mine/tribu \\
Cobre & 1 & & & \\
\cline { 2 - 5 } Zinc & 0,82 & 1 & & \\
Estaño & 0,93 & 0,5852472 & 1 & 1 \\
Miner/tribu & 0,83 & 0,9067715 & 0,60 & 1 \\
\cline { 2 - 5 }
\end{tabular}

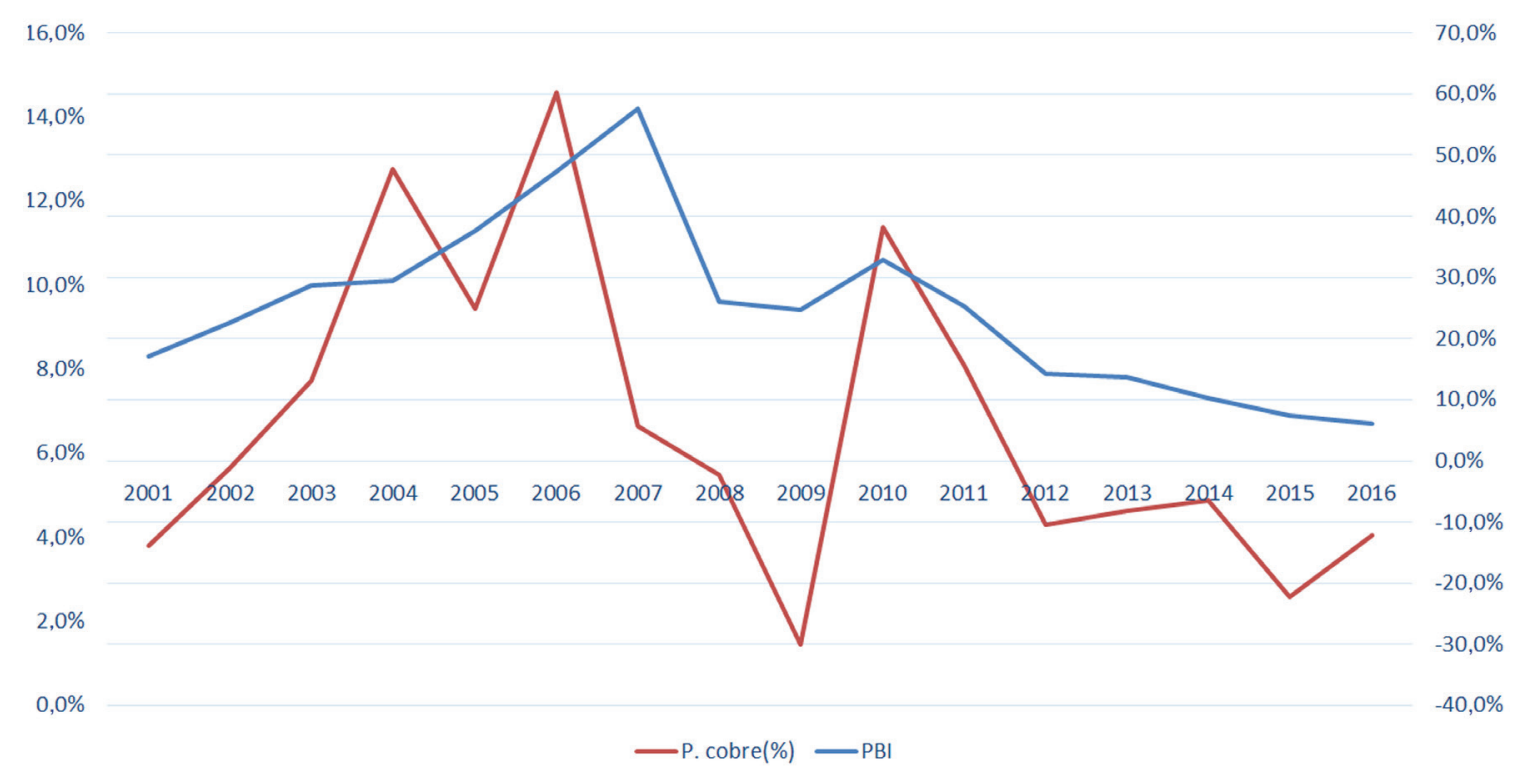

Figura 5. China : PBI y precio del cobre ( Var\%)

Fuente: Elaborado por Autor. 
El coeficiente de correlación entre el PBI y la variación porcentual del precio del cobre llega al $63,5 \%$, cifra que evidencia la relación estrecha de estos dos indicadores. Por lo que a la economía subdesarrollada que basa su crecimiento en la exportación de minerales es de alta importancia que el PBI de la China presente señales de fortaleza.

Es conocido que Perú y chile son los principales países productores y exportadores de cobre, pero el grado de duopolio que mantienen ambos países no es suficiente para imponer los precios en el mercado internacional, sino que estas obedecen a las condiciones que impongan los países importadores.

\section{PBI y las exportaciones mineras}

En cuanto a las exportaciones mine- ras, que es parte de las exportaciones tradicionales, por un lado presentan señales de sensibilidad debido a los vaivenes del mercado internacional y por otro lado se constituyen en la principal plataforma exportadora $y$ que da sustento al PBI y a la balanza comercial.

Es conveniente señalar que el flujo de divisas que se generan por esta actividad es el doble de las exportaciones manufactureras. La posición estratégica de la minería es crítica, de sus resultados no solo depende el flujo de divisas, sino también da sustento a los ingresos tributarios que se derivan de las cuentas de explotación de las empresas mineras.

En la Figura 6 se aprecia con claridad, la posición estratégica de la minería. Si se hace un análisis comparativo con las demás actividades de exportación de tipo tradicional sin duda que sobresale la exportación minera, que en promedio genera divisas por $20 \mathrm{mil}$ millones de dólares, el cual equivale al $70 \%$ de lo que exporta el país a los mercados internacionales.

La volatilidad de las exportaciones también se hace evidente en los años analizados, las cifras oscilan entre 17 mil y 27 mil millones de dólares, las mayores cifras responden a los buenos precios de los productos mineros, pero también hay cifras que señalan la contracción del mercado internacional, representado por la China y otros países demandantes de commodities.

El grado de incertidumbre y volatilidades de los mercados globales es la causal de la volatilidad de los precios de los minerales.

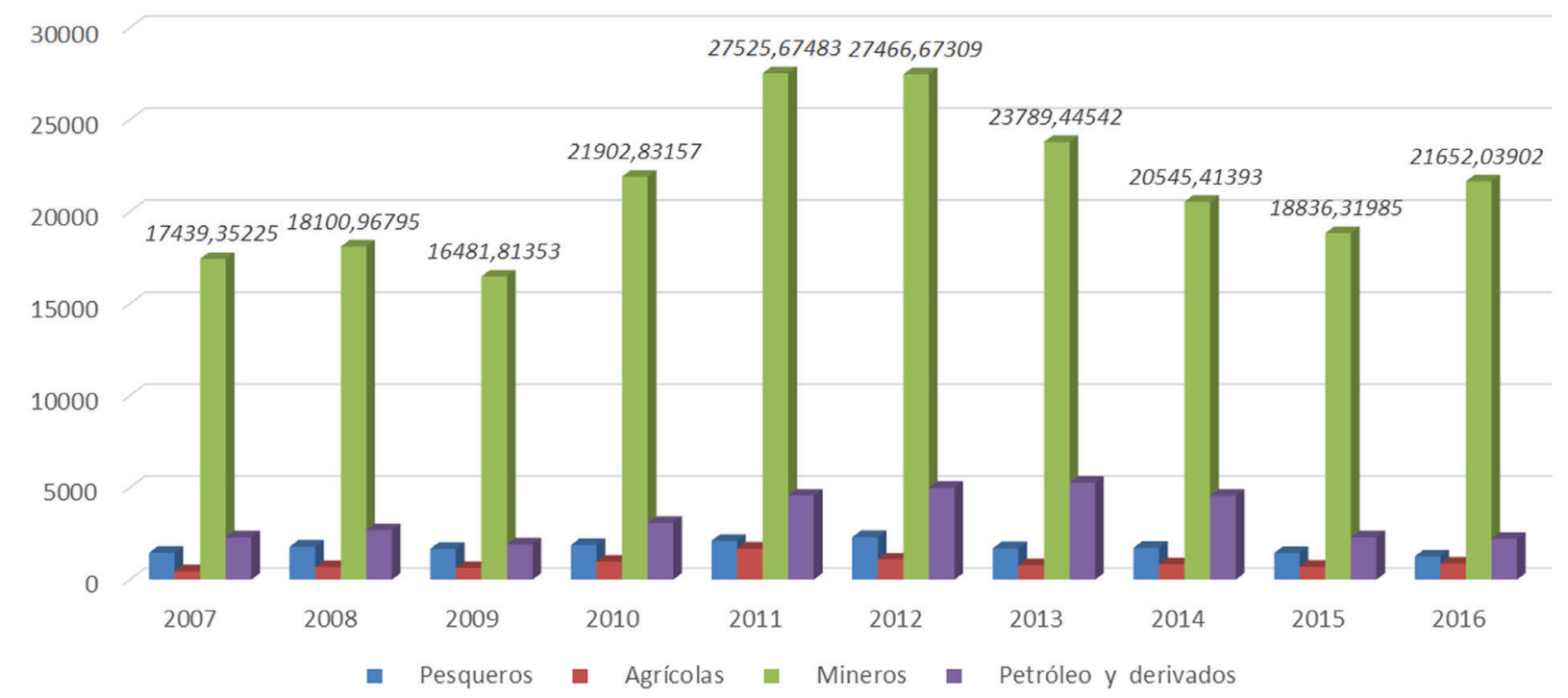

Figura 6. Exportaciones tradicionales por tipo de producto (2007-2016)

Fuente: Elaborado por Autor.

Mantener un grado de correlación del $70 \%$ entre las exportaciones y el PBI, es una clara evidencia de la alta influencia del sector exportador de minerales en el crecimiento económico y que en cierta forma proyectan la alta dependencia de la economía al comportamiento del mercado global, básicamente a los resultados que puedan obtener dos países, la China y Estados
Unidos. Este grado de asociatividad el cual es medido por el coeficiente de correlación $(\mathrm{R})$ y de determinación $\mathrm{R}^{2}$ se puede observar en la Imagen $7 \mathrm{cu}$ yas tendencias entre ambos indicado- 
res tienen la misma dirección. La volatilidad de estos indicadores, el cual estadísticamente es cuantificado por la desviación típica también presentan las mismas señales, características que se da por su alta dependencia. Un hecho que cabe destacar es la elevada participación del cobre, del oro y del zinc en los ciclos económicos.

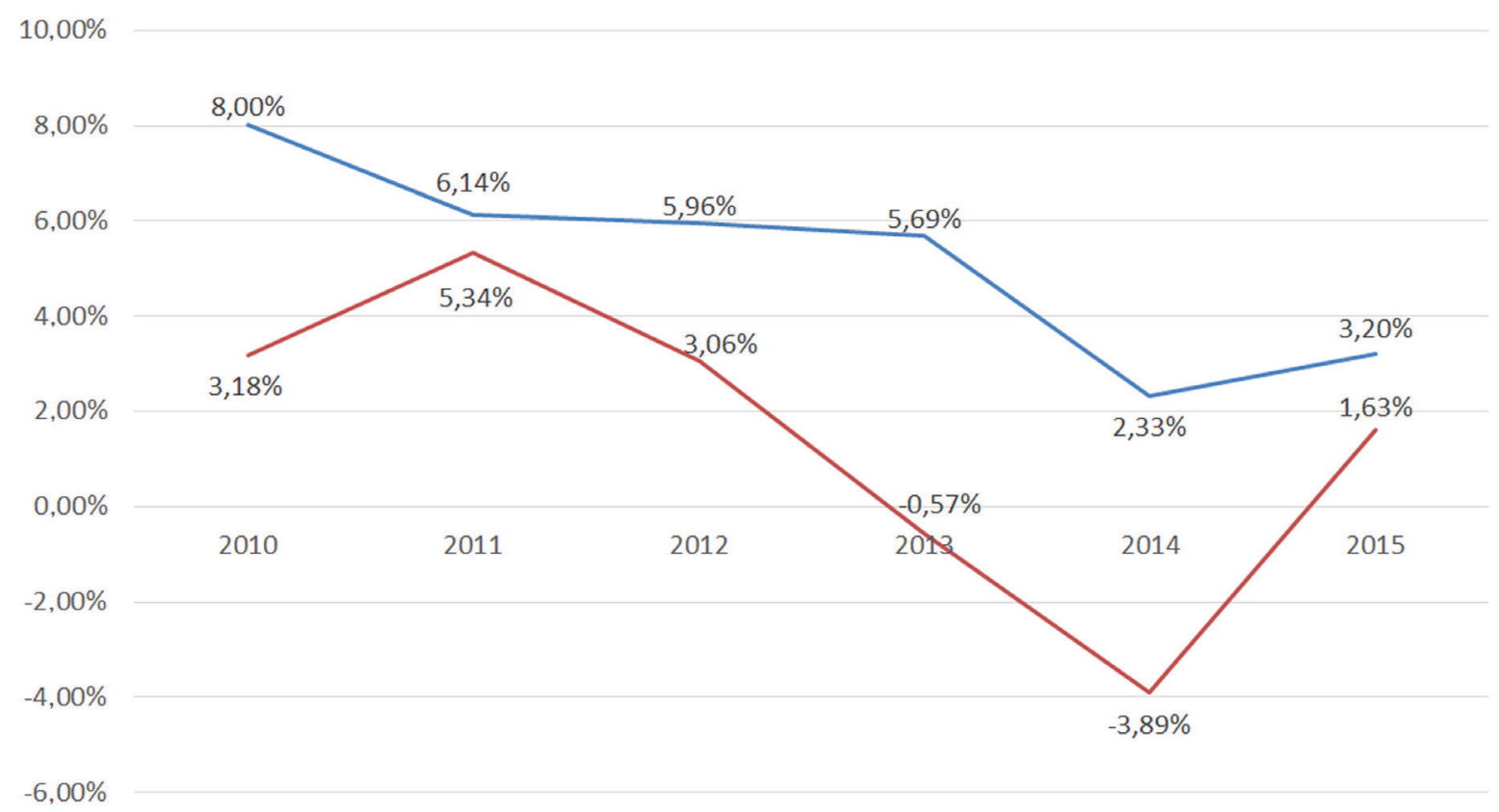

- $\mathrm{PBI}$-EX. MINERA

Figura 7. PBI y exportaciones mineras ( var\%): 2010-2015

Fuente: Elaborado por Autor.

Bajo las cifras analizadas y por la importancia del sector minero en la economía es imprescindible la unión de esfuerzos entre el gobierno, creando plataformas legales inteligentes e infraestructura de transporte $y$ las empresas extractivas a través la implementación de políticas de responsabilidad y buen gobierno, con la intención de crear una dinámica exportadora que sustente los demás actividades económicas del país.

Por último la relevancia de la actividad minera no solo se puede apreciar en el comportamiento del PBI, que por cierto es de alta significancia, sino también en la recaudación tributaria, específicamente en lo que se refiere al impuesto a la renta, por ello las cuentas fiscales en épocas en la cual los precios de las materias primas se deprecian en el mercado internacional muestran señales de debilidad o deterioro vulnerando de esta forma las finanzas gubernamentales. El comportamiento cíclico de los minerales el cual depende de las fuerzas de mercado, condiciona los flujos de ingresos que percibe el gobierno para sustentar sus desembolsos corrientes y de capital, por ello el recorrido de los precios del cobre, del oro, de la plata, zinc entre otros productos son factores críticos que inciden en el pago de impuestos de las principales empresas exportadoras de minerales, como es conocido estas organizaciones cuentan con mayores capacidades tributarias cuando los precios de los commodities experimentan comportamientos alcistas cuyo efecto transmisión inclusive se proyecta en las cotizaciones de las acciones.

\section{DISCUSIÓN}

Las economías subdesarrolladas se han especializado en la exportación de materias primas, si bien esta actividad ha generado importantes flujos de divisas dando sostenibilidad a este mercado, asimismo al fortalecimiento de las empresas y cuentas fiscales de los gobiernos, pero los países que han 
basado su crecimiento bajo este tipo de modelo no han podido resolver sus graves deficiencias estructurales que se observen en su frente interno.

La volatilidad de los precios de las materias primas, como lo minerales están condicionada a las fuerzas del mercado, por ello en épocas de recesión o estancamiento de la economía mundial, la caída de las cotización de los commodities se hace evidente, hecho que va afectar los flujos de exportación castigando además las cuentas macroeconómicas, especialmente las fiscales, como son los ingresos tributarios ya que las empresas exportadoras tendrán menor capacidad contributiva, materializado en un menor pago por impuesto a la renta, generándose por ello, un espacio de vulnerabilidad de las cuentas fiscales del Gobierno Central, por ello, la presión tributaria muestra elevada correlación con el comportamiento cíclico de estos recursos primarios en los mercados globales.

La exportación de materias primas se configura en el principal aportante en la formación del PBI, especialmente el comportamiento de este indicador macroeconómico está sustentado por la exportación de productos mineros, que si bien no han ejercido mayores efectos multiplicadores para corregir las asimetrías internas, pero si se han convertido en una plataforma para sustentar la sostenibilidad del PBI y el ingreso de divisas.

\section{REFERENCIAS BIBLIOGRÁFICAS}

Dornbush, F. (2015). Macroeconomía. (12 Ed.). México DF, México: Editorial MacGraw Hill.

Ferrufino, R. (2007). Maldición de los Recursos Naturales. Enfoque y Teorías y Opciones. La Paz, Bolivia: Fundación milenio.
Nicholson, W. \& Snyder, C. (2015). Teoría microeconómica, Principios básicos y aplicaciones. (11 Ed.). México DF, México: Editorial Cengage Learning

Parkin M, Loria E. (2010). Microeconomía. (9 Ed.), México D.F, México: Editorial Pearson.

BCRP. (2008 - 2016). Memorias anuales. Lima, Perú: Banco Central de Reserva del Perú. Recuperado de http:// www.bcrp.gob.pe/publicaciones/memoria-anual.html

BCRP. (2008 - 2016). Notas semanales. Lima, Perú: Banco Central de Reserva del Perú. Recuperado de http://www. bcrp.gob.pe/publicaciones/nota-semanal.html 